\title{
CECILIA SHERIDAN
}

\section{Anónimos y desterrados. La contienda por el sitio que llaman de Quauyla, siglos XVI-XVIII}

CIESAS, Miguel Ángel Porrúa, México, 2000.

Susan M. Deeds

$\mathrm{D}$ EBIDO a que mis propias investigaciones tratan de la historia de varios grupos indígenas del noroeste colonial, o de la Nueva Vizcaya, la región que colindaba Coahuila al poniente, este libro resulta para mí espede vista comparativo. Voy a comenzar por situarlo en el contexto de la historiografía colonial del norte de México $\mathrm{y}$ de otras regiones fronterizas.

En la última década, un creciente número de estudios se ha dedicado a recuperar la historia de los grupos indígenas de América y por consecuencia explicar por qué algunos grupos persistieron después de la conquista y otros no. En su mayoría, estos estudios se enfocan en los pueblos indígenas sedentarios que tenían organizaciones sociales complejas y algunos de ellos todavía existen hoy como etnias, mientras que los grupos semi-sedentarios o nómadas no han recibido la

SUSAN M. DEEDS: Northern Arizona University.

misma atención por dos razones fundamentales: la primera por la relativa escasez de fuentes documentales que impide hacer un análisis detallado, y en segundo lugar porque la mayoría de estos grupos desaparecieron como entidades indígenas definidas.

Sin embargo, esta situación ha cambiado con algunas investigaciones, como por ejemplo la de Ignacio del Río sobre Baja California, la de Cynthia Radding sobre Sonora, la de Chantal Cramaussel y Salvador Álvarez sobre la Nueva Vizcaya, y varias otras que tratan de regiones fronterizas del cono sur y del Amazonas en Sudamérica. Pero hasta ahora nos faltaron estudios para comprender el noreste de México, la región colonial del país menos conocida. Por todo esto, es muy importante el libro de Cecilia Sheridan que resulta ser el más detallado y analítico que tenemos sobre "las culturas del desierto". La autora indaga entre las relaciones nudosas de centenares de grupos "nómadas" con las misiones franciscanas, así como los esfuerzos de los españoles para dominar el espacio o territorio de esos indios. Nos enseña con mucha claridad el largo y contencioso proceso - "a guerra y sangre"que dio como resultado la desaparición de muchos grupos indígenas quienes opusieron una feroz resistencia a la conquista a lo largo de dos siglos.

Basándose en fondos documentales encontrados en una variedad de archivos mexicanos, Sheridan estudia la diversidad indígena del noreste para averiguar el destino de estos grupos nativos durante el proceso de la conquista. Implícitamente, su trabajo también desbarata dos mitos principales de la historiografía colonial del noreste: uno tiene que ver con el estereotipo de los indios llamados "chichimecas" que son siempre retratados de una manera ahistórica, homogénea, e identificados como salvajes cazadores-recolectores y que tuvieron poco significado en la historia de la Nueva España. Han sido invisibles en un paisaje que se suponía ser casi vacío de recursos humanos. La otra tradición que resulta ser cuasi mítica es la hipótesis de François Chevalier sobre 
los hacendados ricos y poderosos y los orígenes del latifundio. Poco a poco, las nuevas investigaciones han mostrado que este modelo no es muy pertinente para muchas partes de la Nueva España incluyendo al noroeste. Se había pensado que el modelo era más convencedor en el caso del noreste; sin embargo el libro de Cecilia nos revela que hubo mucho más diversidad en la adquisición y tenencia de la tierra que lo que pretende el trabajo de Chevalier.

La evolución del noreste en la época colonial no se puede apreciar sin entender claramente el medio ambiente y el uso de los recursos naturales desde el período prehispánico. Este libro nos proporciona esa información de modo muy detallado e incluyendo muchos ricos retratos etnográficos de los innumerables grupos indígenas. Con estas aportaciones los indios pierden la invisibilidad y se observa específicamente cómo las imposiciones coloniales transformaron esa zona aridísima.

A través de cuatro etapas de conquista y colonización, Sheridan relata la historia de esta frontera de guerra y sangre, destacando el permanente estado de tensión y conflicto y la desaparición de los grupos nativos, a lo largo del período colonial. Nos enseña también el impacto que tuvieron los cambios en la política de la corona española hacia el noreste. Después del siglo XVI la corona se opuso explícitamente a la esclavitud y la aniquilación de los indios, aunque en realidad las políticas oficiales tendían a promover su subordinación de manera muy violenta, si no su exterminio. La excepción fue la fase de adoctrinamiento por medio de las misiones franciscanas en el siglo XVIII; no obstante,

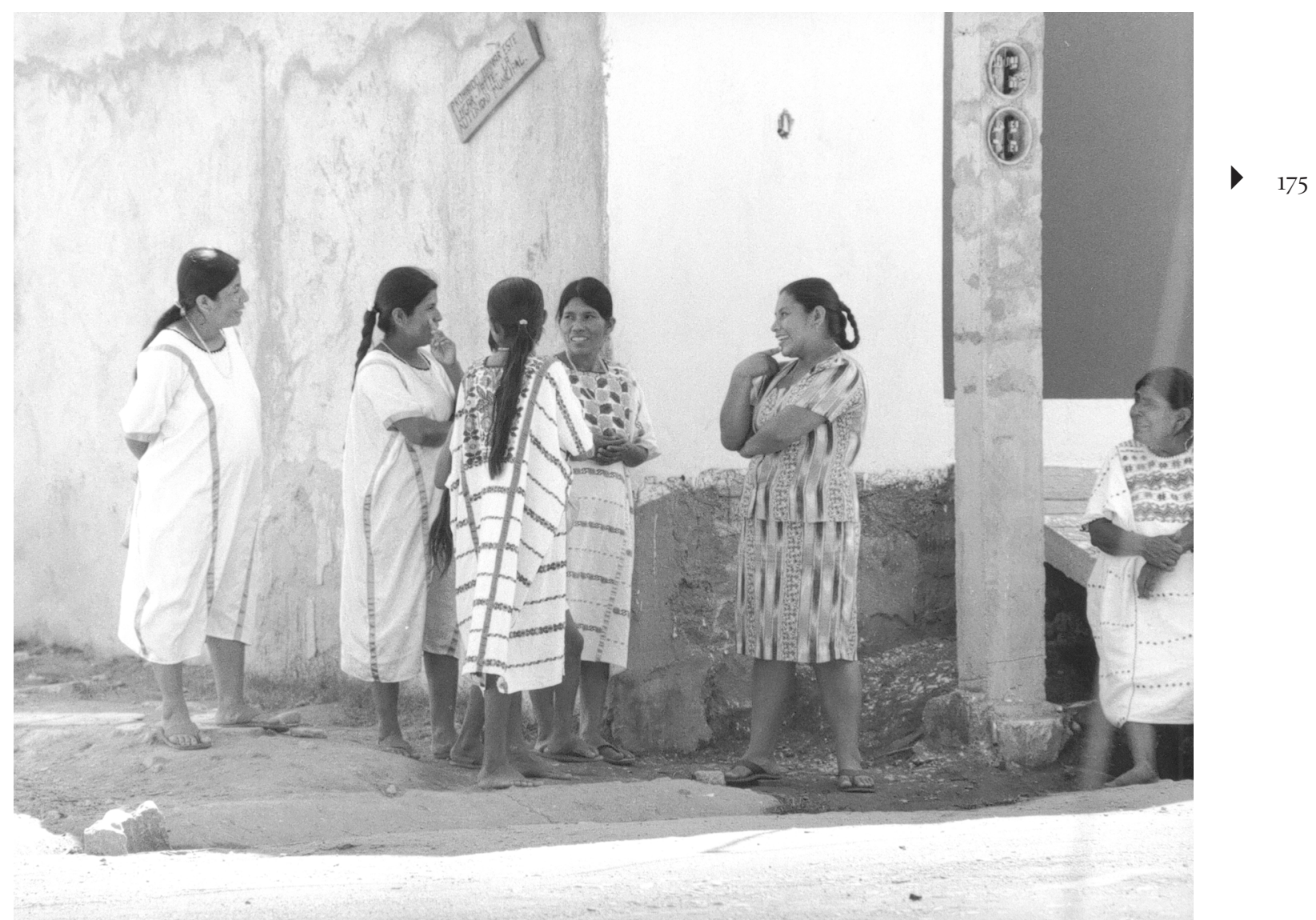


la autora muestra cómo ni siquiera ésta era una forma pacífica de colonización, ya que era respaldada por soldados españoles y tlaxcaltecas. Aun cuando los oficiales reales intentaron prohibirlo, los oficiales locales querían acabar con los nativos o provocar que ellos se mataran entre sí. En aquella zona fronteriza, las elites políticas y socioeconómicas consiguieron contradecir la voluntad real con bastante facilidad, especialmente cuando emplearon sus propios recursos materiales en la empresa de conquistar y gobernar. Además, los oficiales militares adquirieron enorme poder y extensos terrenos en las áreas de los presidios y misiones.

Por lo general, Anónimos y desterrados... apoya la hipótesis que argumenta que la misión y el presidio eran instituciones fronterizas primordiales. Sheridan plantea que las misiones dieron un mayor impulso a la colonización por gente no indígena y destaca la importancia que tuvieron también los presidios. No fue el caso, por ejemplo, de la Nueva Vizcaya donde los asentamientos mineros y las estancias agrícolas y ganaderas precedieron a las misiones. Esta diferencia nos lleva a pensar en otras distinciones entre esas dos regiones del norte. Si bien ni los grupos semisedentarios de Nueva Vizcaya ni los nómadas de Coahuila quisieron dar servicio personal a los conquistadores, en la Nueva Vizcaya hubo desde el principio más necesidad de mano de obra para la economía minera y los españoles dispusieron de más recursos para subyugar a los indígenas que ya tenían una tradición en alguna medida agrícola. En el caso de

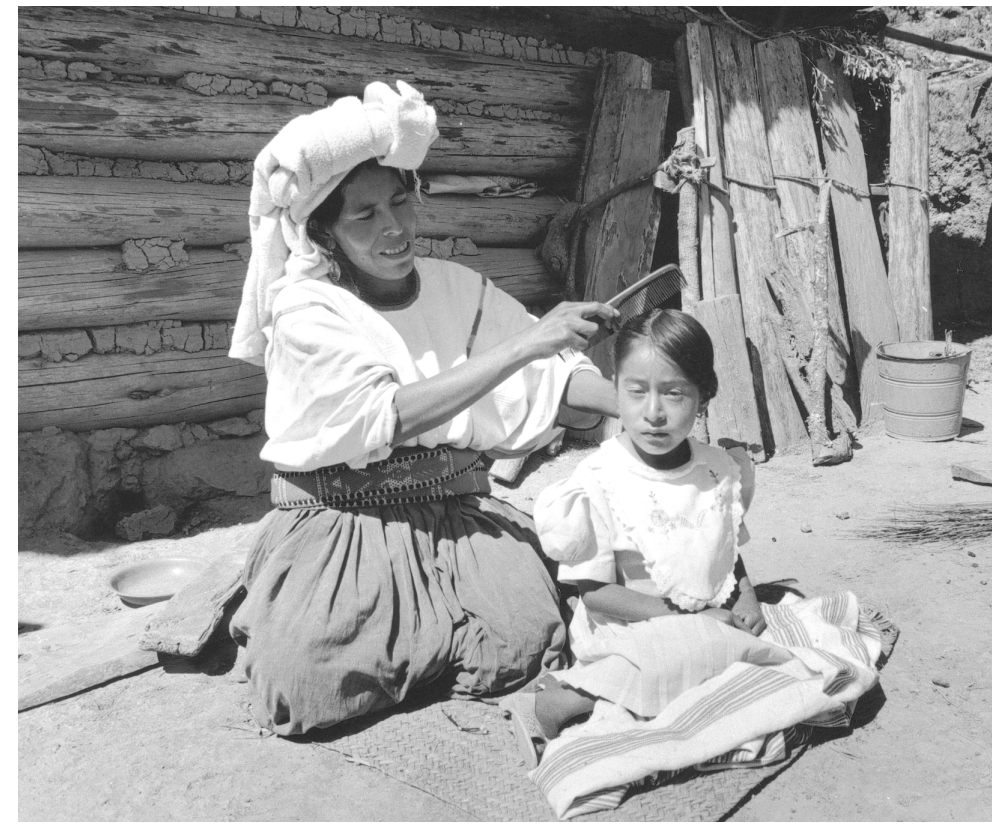

Espíritu Santo, mixe, 1995

Coahuila como los nativos fueron muy resistentes también fueron más dispensables. No sería hasta el siglo XVIII cuando la economía española de Coahuila alcanzó un nivel semejante de productividad a la de Nueva Vizcaya en el siglo XVII.

Sheridan describe una empresa misional franciscana que fue bastante inestable y llena de conflictos entre los misioneros mismos, debido entre otras cosas a que eran representantes de los diferentes colegios franciscanos (de Jalisco, Querétaro y Zacatecas). Distingue entre la colonización misional y la de los seculares y asevera que los franciscanos no alteraron tanto la complicada organización territorial nativa.

También considera a los franciscanos como los más constantes protectores de indios, siempre opuestos a los oficiales civiles y militares en cuestiones como el uso y abuso de mano de obra indígena. Aquí hay otro contrapunto con la situación de Nueva Vizcaya donde los misioneros jesuitas cooperaron con los civiles para proporcionarles fuerza laboral por medio del sistema de repartimiento. Muchas de las misiones franciscanas fracasaron por la continua movilidad de los indios y porque los nativos aprendieron a usarlas como lugares de refugio. También aprovecharon la estancia temporal en las misiones para conocer las costumbres del enemigo y resistirlo mejor. Aun cuando las misiones fueron más fructíferas en productos agrícolas y ganaderos, fracasaron por estar en conflicto con los españoles sobre el acceso al agua y, más tarde, a la mano de obra. La autora explica cómo afectó a esta zona la secularización de las 
misiones en términos mayormente locales; en este caso, creo que podía haber enriquecido el contexto si lo hubiera hecho comparativo y global como un fenómeno de la época borbónica.

Para mí la tarea más formidable que emprendió Cecilia Sheridan fue la de tratar de explicar la diversidad de los grupos nativos de la región: de poner alguna racionalidad a las más de 800 menciones de nombres de grupos. Es casi imposible imaginar la dificultad de entender esta multiplicidad cuando para mí no es fácil clasificar a los cinco grupos de la Nueva Vizcaya que estu- banda. La autora aclara la tendencia de los españoles de subsumir distintos grupos bajo unas entidades casi genéricas. Podía reforzar estos argumentos con la mención de los trabajos sobre tobosos de Salvador Álvarez y Luis Rodríguez que aparecen en el libro Nómadas y sedentarios en el norte de México: Homenaje a Beatriz Braniff, coordinada por Marie-Areti Hers y otros (UNAM, 2000). Nos enseña Sheridan cómo las bandas pequeñas de 20 a 30 personas del período temprano fueron transformadas con el transcurso del tiempo en bandas de 300 individuos. Este proceso fue resultado de

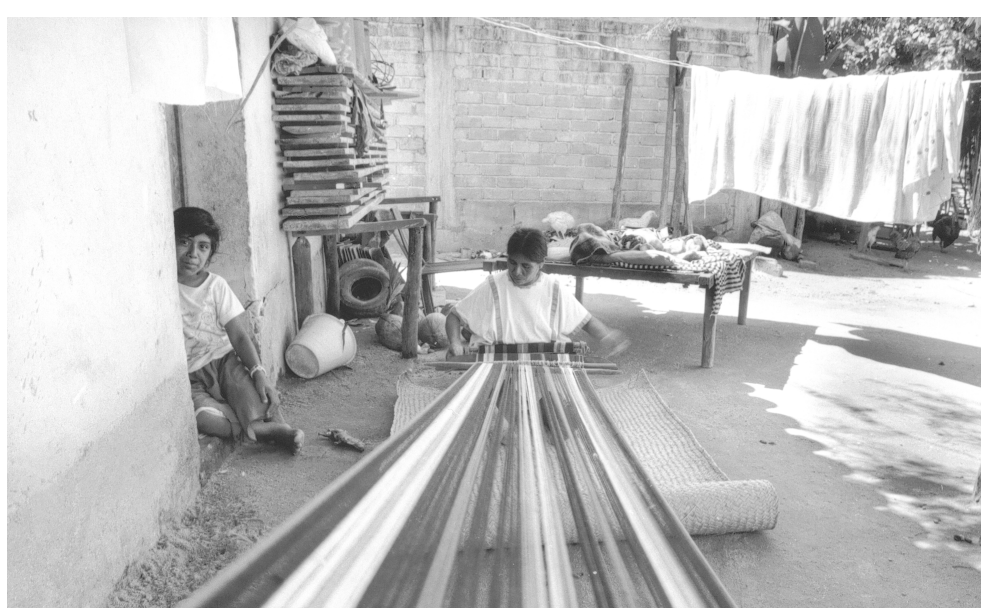

Santa María Zacatepec, tacuate, Vittorio D’Onofri, 1995

dio. Aquí, la autora nos da una explicación muy matizada de los términos de banda y nación y de las condiciones confusas y caóticas en las cuales los españoles dieron nombres para identificar a los grupos. Un problema que enfrenta la autora es que los historiadores no están de acuerdo sobre el significado de los términos nación y alianzas entre los grupos nativos, aun entre aquellos que antes habían sido enemigos. A través de su esquema para analizar estas menciones por épocas, vemos muy claramente que la tasa de extinción de grupos aumentó conforme creció la población no nativa.

Sheridan calculó que para fines del siglo XVIII la población indígena se había reducido en más de 98 por ciento desde los primeros contactos. Con respecto al origen de tan alta mortalidad, la autora sugiere causas naturales, bélicas y culturales. En el caso de estos grupos sería imposible estimar el peso de cada una, pero al fin las cifras de la caída demográfica son aún más altas que en el caso de la Nueva Vizcaya donde podemos decir que las epidemias fueron la causa primaria.

Al final de cuentas, los españoles llegaron a dominar el espacio de Coahuila porque sólo ellos supieron "poblar para usar". La negativa de parte de los nativos a someterse a un régimen tan ajeno terminó no sólo en su aniquilación cultural sino biológica. Aunque se aprovecharon de algunos elementos de la cultura material de los invasores como el caballo y otros animales que les ayudaron a resistir mejor, no pudieron expulsar a los españoles de los territorios que les habían sustentado desde tiempo inmemorial. Al mismo tiempo, como dice nuestra autora, escogieron no acomodarse a una nueva cultura, "tan ajena que el calor de los infiernos prometía una mejor vida" y fueron desapareciendo en gran parte por causa de su propia resistencia agresiva.

Para concluir, quisiera felicitar a Cecilia Sheridan por esta adición tan importante no sólo para la historia general y regional de México, sino también para la historia comparativa. Nos ha dado una aportación sumamente valiosa para explicar las consecuencias tan variadas de la conquista europea sobre los diversos grupos indígenas a través de las Américas. 